\title{
Correction to: Minimal ovarian stimulation is an alternative to conventional protocols for older women according to Poseidon's stratification: a retrospective multicenter cohort study
}

\author{
Mauro Cozzolino $^{1,2,3}$ (D) Gustavo Nardini Cecchino ${ }^{3,4,5} \cdot$ Ernesto Bosch $^{6} \cdot$ Juan Antonio Garcia-Velasco ${ }^{1,3,7}$. \\ Nicolás Garrido ${ }^{1}$
}

Published online: 30 April 2021

(C) Springer Science+Business Media, LLC, part of Springer Nature 2021

Correction to: Journal of Assisted Reproduction and Genetics https://doi.org/10.1007/s10815-021-02185-2

The original article unfortunately contained an error. Figure 2 and Figure 3 are inverted but the legends are correct.

The original article has been corrected.

Publisher's note Springer Nature remains neutral with regard to jurisdictional claims in published maps and institutional affiliations.

The online version of the original article can be found at https://doi.org/ $10.1007 / \mathrm{s} 10815-021-02185-2$

Mauro Cozzolino

mauro.cozzolino@ivirma.com

1 IVI Foundation, Avenida Fernando Abril Martorell, 106 - Torre A, Planta $1^{\text {a }}, 46026$ Valencia, Spain

2 Department of Obstetrics, Gynecology and Reproductive Sciences, Yale School of Medicine, 310 Cedar St, New Haven, CT 06510, USA

3 Rey Juan Carlos University, Calle Tulipán, 28933 Móstoles, Madrid, Spain

4 Department of Gynaecology, Federal University of São Paulo, São Paulo, Brazil

5 Department of Reproductive Medicine, Mater Prime, São Paulo, Brazil

6 IVI-RMA, Valencia, Spain

7 IVI-RMA, Madrid, Spain 